Article

\title{
Solutions to Marine Pollution in Canary Islands' Ports: Alternatives and Optimization of Energy Management
}

\author{
Manuel Uche-Soria ${ }^{(D)}$ and Carlos Rodríguez-Monroy * \\ Department of Industrial Organization, Business Administration and Statistics, \\ Technical University of Madrid c/ José Gutiérrez Abascal, 2, 28006 Madrid, Spain; m.uche@alumnos.upm.es \\ * Correspondence: crmonroy@etsii.upm.es; Tel.: +34-91-3364265; Fax: +34-91-3363005
}

Received: 18 March 2019; Accepted: 29 March 2019; Published: 2 April 2019

\begin{abstract}
The study of waste generated in ports is a vitally important issue to reduce marine pollution and improve port management systems. In this article, the authors study the management of solid waste generated in the ports of the Canary Islands. For this purpose, a waste management model based on the circular economy is developed. With this model, it is possible to reduce pollution in the port areas of the capital's islands, increase the fraction of recycled waste and obtain additional energy for the ports. The interest of this study lies in the singularities of these islands with respect to the geographic limitations that make them weak energy environments. The proposed solution to solve the current problems and achieve a zone of zero waste (throughout the port of Santa Cruz and its industrial estate) has two main phases: the first, in which solid waste is processed and a part is recycled, and the second, which consists of recovering the energy of the converted fuels. The advantages of the application of this model are that $\mathrm{CO}_{2}$ emissions are reduced, energy savings are realized, waste management is improved in these environments (the recycling fraction is increased considerably), and new jobs are created. This model also contributes to the development of the Special Territorial Plan for Waste Management of the Canary Islands, in accordance with the policies of the European Union required for the coming years.
\end{abstract}

Keywords: marine environment; MARPOL; isolated electricity system; circular economy; shipping and environment

\section{Introduction}

\subsection{Motivation}

When analyzing the evolution of the principal energy magnitudes in electrically isolated environments, as in the Canary Islands' isolated electricity system (IES), it is remarkable that internal production contributes only a tiny fraction of the primary energy. This amount refers to the total contribution of all the main types of renewable energy available in the archipelago (wind, photovoltaic solar, solar thermal, hydro-wind, mini-hydro, and landfill biogas). In comparison to the Spanish mainland, the lack of major hydroelectric facilities (except for the recent start-up of a new hydro-wind installation called "Aprovechamiento Hidroeólico de El Hierro") limits the participation of renewable energies. Their contribution remains low, especially when compared to other more advanced energy generation systems around Europe.

The total participation of these renewable energies has been stable for years [1]. This is partly influenced by the weather conditions, which change so easily in islands with such abundant micro-climates. Specifically, in the last year for which the Canary Islands' Government has given 
official data (see Table 1), the total primary energy barely reached $1.40 \%$, with a trend approaching this figure in previous years.

Table 1. Main energy magnitude statistics in the Canary Islands. Units: (Tep).

\begin{tabular}{ccccccc}
\hline Year & $\begin{array}{c}\text { Internal } \\
\text { Production }\end{array}$ & $\begin{array}{c}\text { Inputs- } \\
\text { Outputs }\end{array}$ & Bunkers & $\begin{array}{c}\text { Stock } \\
\text { Change }\end{array}$ & $\begin{array}{c}\text { Primary } \\
\text { Energy }\end{array}$ & $\begin{array}{c}\text { Final } \\
\text { Energy }\end{array}$ \\
\hline $\mathbf{2 0 1 2}$ & 60,785 & $6,982,391$ & $(-)) 2,416,715$ & 204,654 & $4,831,116$ & $3,349,622$ \\
$\mathbf{2 0 1 3}$ & 63,959 & $7,070,635$ & $(-) 2,354,418$ & 50,882 & $4,831,059$ & $3,341,420$ \\
$\mathbf{2 0 1 4}$ & 66,397 & $6,395,707$ & $(-) 1,977,770$ & 77,740 & $4,562,073$ & $3,366,465$ \\
$\mathbf{2 0 1 5}$ & 67,372 & $7,127,494$ & $(-) 2,392,608$ & $(-) 271,968$ & $4,530,291$ & $3,358,818$ \\
$\mathbf{2 0 1 6}$ & 68,189 & $7,015,082$ & $(-) 2,452,172$ & 97,837 & $4,728,936$ & $3,504,302$ \\
$\mathbf{2 0 1 7}$ & 70,491 & $7,321,567$ & $(-) 2,321,567$ & 15,489 & $4,900,683$ & $3,634,526$ \\
\hline \multicolumn{7}{c}{ Annual Variation (\%) } \\
\hline $\mathbf{1 7 / 1 6}$ & 3.38 & \multicolumn{7}{c}{2.23} \\
\hline \multicolumn{7}{c}{4.37} \\
\hline
\end{tabular}

In fact, petroleum derivatives supplied to final users absorb the majority of the final energy demand, reaching $80.02 \%$ of the total in 2017 . The remaining $19.98 \%$ is split into electricity $(19.75 \%)$ and solar thermal power $(0.23 \%)$. The details of the Canary Islands energy system structure and its development regarding factors like supply security (reliability), the restricted spread of self-supplied energy, the share of renewable energies in the regional mix, energy efficiency and savings can be seen in this simplified diagram of the energy balance of the Canary Islands.

Studying Figure 1, elaborated with the latest data from the Government of the Canary Islands [1], some interesting aspects should be pointed out. On the one hand, according to [2-6], there is a need to plan and join forces to develop and implement new energy generation systems. These should achieve lower costs for these isolated systems and in turn resolve issues arising from the local peculiarities. For this, a strategic energy plan covering isolated territories like the Balearic Islands and the Canaries is needed, that does not only focus on the context of the Spanish mainland. This must be translated into new actions like improvements in the existing specific regulations, making reasonable electricity charges possible [7-9] in isolated environments. On the other hand, taking studies like [10] and [11] as references in the context of an archipelago like the Canary Islands, this strong reliance on crude-oil based energy supplies readily brings to mind interactions between the maritime operations in these docks and the environment. Indeed, the Canaries have a substantial sea traffic density in relation to their population. This leads to considering the possibility of channeling the residues generated by maritime traffic towards a mode of electrical energy production that is able to fulfill some of the needs of the port.

In this article, ship-generated waste refers to all waste, including waste-water (for example, bilges), and non-loading wastes produced during ship operation. This includes those derived from fishing boats, leisure craft, and cargo wastes. In the Canary Islands' ports, the main wastes are generated by cargo, machinery, and maintenance, as well as by passengers and crew. This leads to environmental consequences viewable from different perspectives according to their three general categories: hydrocarbon, organic, and floating litter.

The effects of hydrocarbons are many and varied; in particular, they lower the penetration of sunlight into the water, affecting different living organisms (most visibly in birds' feathers, fish gills, and sea-bottom communities). They release other toxic substances to the ecosystem, affect ship and dock infrastructures, and finally, damage the public image of maritime transport and docks in general. Organic matter in excess can have similar consequences on the marine ecosystem, besides others like raising primary production and the oxygen usage rate, anoxia (oxygen debt) and other effects on the dissolved oxygen. Floating litter is no less harmful. It has been estimated that 6,400,000 $\mathrm{m}^{3}$ is thrown into the sea annually from vessels. The waste input from land into the sea is estimated at $700,000 \mathrm{~kg} / \mathrm{day}$, and up to 30 floating objects $/ \mathrm{km}^{2}$ have been counted by observation from ships. Other 
calculations estimate 150 times more plastics in marine depths than floating. In addition, 1000 items per linear meter can be found floating on the Canary Islands' beaches. A microscopic estimation puts the problem on a wider range: $8,000,000$ per square $\mathrm{km}$.

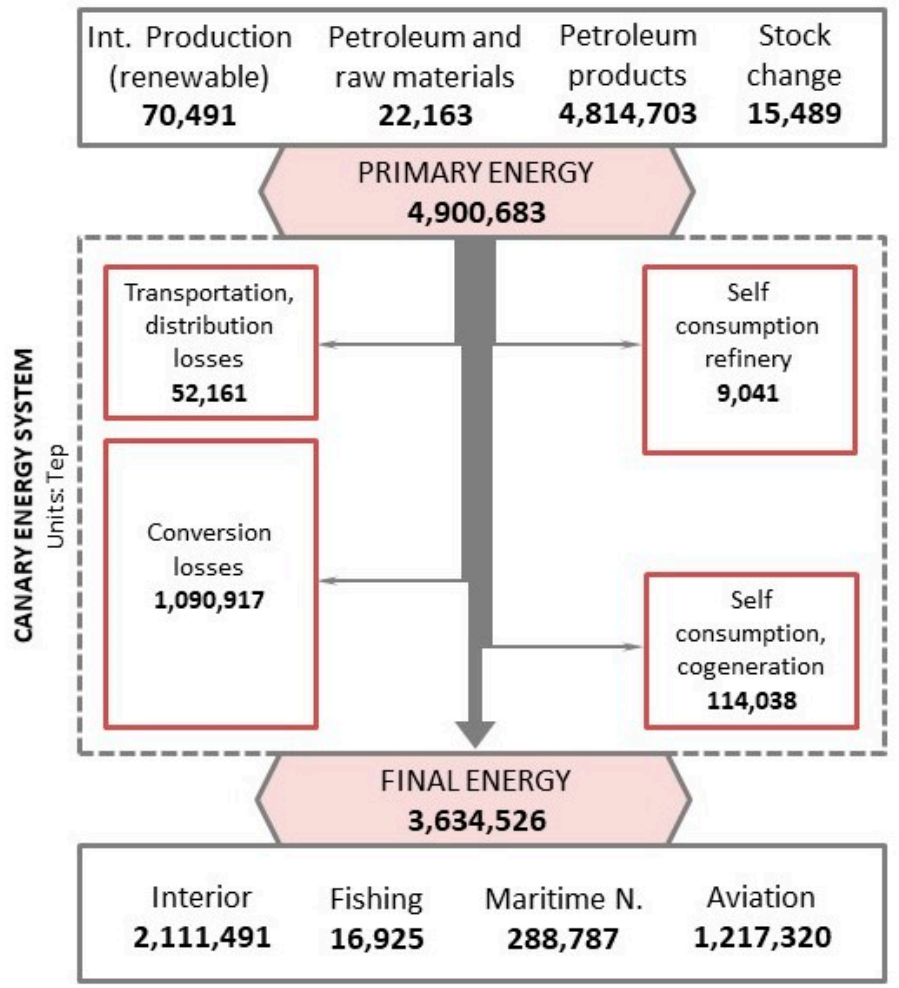

Figure 1. The energy balance of the Canary Islands (2017) (source: authors).

Problems with managing general waste in the marine environment are nothing new. Figure 2 shows the difference between its management in land and sea environments, which provides some idea of the great complexity of adapting such systems between these environments. This is even more so in isolated systems like islands, where waste flows are much smaller, hampering the implementation of efficient technological solutions viable on a larger scale.

\begin{tabular}{|c|c|c|}
\hline $\begin{array}{ll}\text { MARPOL I } & \text { Hydrocarbons } \\
\text { MARPOL II } & \text { Chemicals } \\
\text { MARPOL IV } & \text { Sewage } \\
\text { MARPOL V } & \text { Waste } \\
\text { MARPOL VI } & \text { Atmospheric P. }\end{array}$ & $\rightarrow$ & $\begin{array}{l}3 \text { CER codes } \\
+ \text { de } 30 \text { CER codes } \\
\text { Not considered CER codes } \\
+ \text { de } 30 \text { CER codes } \\
2 \text { CER codes }\end{array}$ \\
\hline 5 different types of waste & $\begin{array}{l}\text { PORT AS } \\
\end{array}$ & More than $\mathbf{7 0}$ different types \\
\hline Marine environment & $\begin{array}{c}\text { MANAGEMENT SYSTEM } \\
\text { ADAPTER }\end{array}$ & Land environment \\
\hline
\end{tabular}

Figure 2. Differences between marine and terrestrial waste management.

That being said, other common marine waste-management issues must be borne in mind. Firstly, wastes and their quantities are heterogeneous, and mixes of different kinds of waste are common, making them more difficult to manage (MARPOL I with rags, glass, ceramics, plastics, wood, metals, paper and cardboard). Secondly, there are marine vessel wastes not considered as such, e.g., pyrotechnical waste-fireworks/flares, vegetables oils, bilge or other polluting substances, and other refuse not considered MARPOL (e.g., materials such as discarded electric batteries, remains 
of material from maintenance work carried out on board or cargo and fishing waste). Lastly, ship waste requiring specific management can be mishandled, which combined with inappropriate reception methods for small vessels often make management systems difficult to implement.

\subsection{Literature Review}

The existing literature on marine pollution in a broad sense is varied and abundant. However, when the object of study is limited to the waste management systems of the ports, there are not so many existing references. Di Vaio et al. [12] conducted a study on management control systems (MCS) to support decision-making by the Port Authority and prevent negative environmental effects in maritime ports. These authors focus their work on the management of information and on the relationship of the different actors for a specific case in Italy, and they emphasize that there is still no MCS that is focused on waste. These same authors indicate in [13] that the current regulations do not specifically provide port operators with help on what effective management tools they can adopt to guarantee environmental protection. On this idea, they develop a proposal of conceptual management in favor of the environmental sustainability of the maritime ports. However, it is true that this proposal, being purely conceptual, lacks practical validation. Also, applied in the case of Nigerian ports, in [14] an integrated model is suggested to reinforce the weak administrative framework of control over marine pollution in port environments. This weakness, as it happens in numerous ports of the world, is the result of the subcontracting of waste management systems. It would be interesting to extrapolate the study to other ports with similar characteristics.

Concerning the existing literature there is a lack of research that evaluates the environmental impact costs of the pollutants generated by routine shipping operations. CE Delft [15] indicates that the external costs generated by transport are quantified for the countries of the European Union and the idea of this study is to provide a guide that can contribute to the development of the EU transport policy. Etkin [16] explains that the risk assessment of almost 52,000 oil spills which occurred in the US inland waterways was carried out. The results of this study revealed that the greatest risk to inland waterways is due to spills in the pipelines, particularly from crude oil pipelines. In this sense, Camphuysen [17] observes that there is a shortage of long-term studies and easily available and comparable information, which limits an understanding of the true impacts of hydrocarbon pollution on marine wildlife. In addition, unfortunately, the available knowledge seems to play a very small role in the orientation of the decision in the planning of the clean-up operations after the oil incidents or in the planning of the aerial inspections of oil at sea. In this sense, a study carried out in Israel [18] analyzes the different ways in which oil spills can affect natural ecosystems and socioeconomic resources along the coast. In this study, it is concluded that, in general, the sensitivity of the Israeli Mediterranean coast to oil spills could be considered moderate, in comparison with other fragile ecosystems. This is mainly due to the morphology of sandy beaches and the high exposure of most types of beaches to natural cleaning processes. Even so, along the south-eastern Mediterranean coast there are ecosystems, habitats, types of coastlines and coastal resources that are sensitive to oil spills. On the other hand, Gómez et al. [19] propose a procedure that combines rigorously selected parameters and indicators to estimate environmental risk in national ports. In this way, port managers and local authorities can hierarchically classify environmental hazards and proceed with the most appropriate management.

From a more economic point of view, Liu and Wirtz [20] delved into the five main categories of different costs after an oil spill and covered the gap from previous analyses by adding research costs. What is clear is that the circumstances surrounding the response to an oil spill incident are complex and unique [21], so predicting the costs of a spill is difficult and arduous.

On the other hand, if attention is given only to what happens in ports, it is easy to see that there are far fewer studies evaluating attractive alternatives and efficient energy management systems. Moreno-Gutiérrez et al. [22] describe and compare various methods to calculate energy consumption and emissions of ships. They also analyze various factors that affect the adequacy of each one and suggest a new method, more adjusted to reality. In addition, the study presented by Kumar et al. [23] 
present a detailed review of the technical aspects, practices and existing standards in the modeling of a port network for the supply of energy from land to ship. This document also mentions modeling through smart grids to facilitate energy supply and the loading of ships' batteries. Finally, Yigit and Acarkan [24] suggest a new approach for the administration of electric power for vessels that use mixed energy sources in ports, considering smart grids. In this study, combinations of photovoltaic energy, wind turbines, energy storage, shore energy and four types of marine fuels were taken into account. The results show that this approach will contribute to the development of concepts of smart boats, green ports and sustainable cities.

To study and propose alternatives for improvement in relation to the management of waste from port environments, it is necessary to resort to the concept of the circular economy. There are many texts that address this concept. Without a doubt, the concept of the circular economy has gained great importance. In an analysis of this term, Kirchherr et al. [25] argued that this concept means many different things for different people and environments. Something that seems common to all definitions is that in order to define this concept, a combination of reduction, reuse and recycling activities are used. On the other hand, the main objective of the circular economy is economic development, followed by the care of environmental quality. On the other hand, Geissdoerfer et al. [26] conceptually relate the circular economy and sustainability. The authors conclude that the circular economy is considered a condition for sustainability, a beneficial relationship or an exchange in the literature. This can be reduced to a different relationship. In addition, this relationship seems to be adequate in order to shed light on the set of complementary strategies that managers and policymakers can adopt.

Finally, delimiting one of the meanings of the circular economy concept to the port area, Carpenter et al. [27] carry out an interesting study in the port of Gävle, Sweden, in which the polluted dredging materials help create new land using the principles of the circular economy. It is interesting how this document shows that the use of the principles associated with the concept of the circular economy can be a viable way to ensure the future of the port and contribute to its sustainability and, in addition, that of the city or region where it operates.

The regulatory framework is well-known, but it is convenient to distinguish here the three levels in which MARPOL wastes are classified (Figure 3). On an international level, there is the 1973 international convention to prevent marine pollution by ships, modified by the 1978 protocol, shortened to "MARPOL 73/78". The five convention annexes contain the rules that are applicable to the diverse sources of contamination caused by ships. The convention was also modified by the 1997 protocol, which approved the sixth annex, but this protocol has not been ratified by a sufficient number of countries for it to come into effect. Several revisions have been made on this regulation, such as the consolidated edition of 2002 [28]. Recently, several amendments to the International Convention for the Prevention of Pollution from Ships (MARPOL) were introduced and entered into force last March [29].

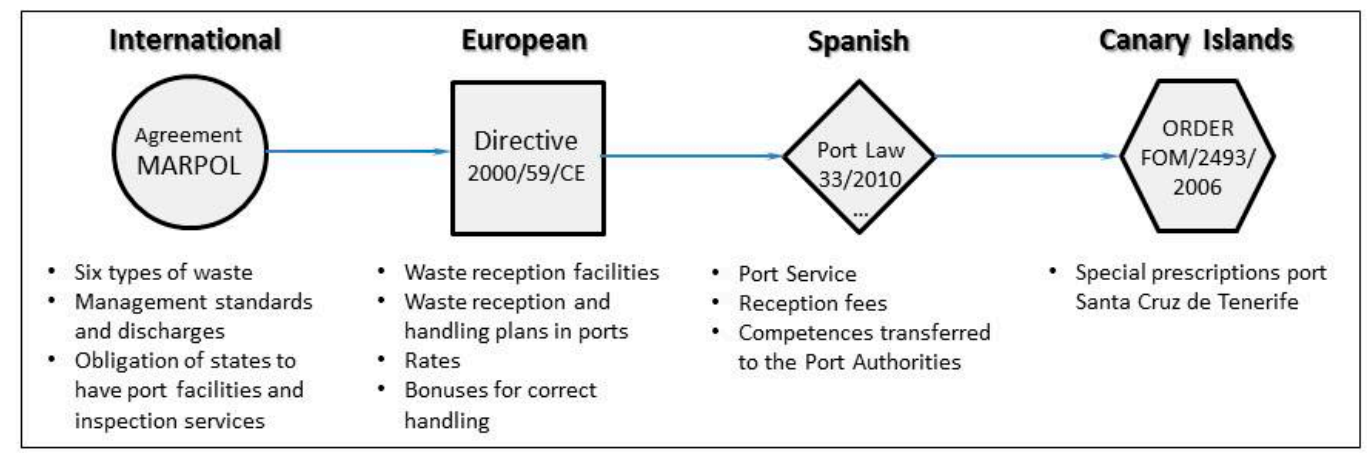

Figure 3. MARPOL wastes regulatory framework.

At the European level, the European Parliament and Council's 2000/59/CE Directive, 27 November 2000 [30], concerning port installations receiving ship and cargo wastes set out a similar set of internal provisions for Spain in Royal Decree 1381/2002, 20 December, conforming the current national port 
regulations [31]. Each port in the country has peculiarities referring to wastes and planning legislation and these are summarized in their respective autonomous regulations. Bellas [32] describes the implementation process and discusses the institutional framework and the main difficulties and challenges encountered so far, in the marine strategy framework [33,34], with emphasis on the Spanish context.

\subsection{Main Contributions}

In this article, a review of the literature on marine pollution and its applicable regulations regarding waste management is carried out. This review lacks the implementation of models that seek to optimize waste management in port areas through a sustainable perspective.

Therefore, the main contribution of this research is the proposal of a model to improve waste management in the ports of the Canary Islands. This model is based on the concept of circular economy and is based on the valorization of port waste in order to obtain energy. This achieves three objectives: (i) it contributes to the conservation of the environment, (ii) it improves an aspect as relevant as the integral management of waste, and (iii) it contributes to energy savings in isolated electrical systems.

\subsection{Structure of the Article}

The article is structured as follows. Section 2 is called Materials and Methods and exposes, in addition to the data and characterizations that have been used, the study model to improve waste management in the port of Santa Cruz de Tenerife. In Section 3 the results of the proposed model are shown. Section 4 corresponds to the discussion and explains the benefits and limitations of the applied model. Finally, conclusions and some recommendations that may also be useful for future research are presented in Section 5.

\section{Materials and Methods}

\subsection{The Model}

The diagram in Figure 4 is proposed to explain the model and the steps of this study. The aim is to meet the port's demand (D) and particularly that of the cruises making a stopover there (C) through energy generated from the collected waste (G1) by means of a gasification process. Any surplus could be commercialized.

The extra energy to cover peaks in cruise and other ship dockings would be provided by liquefied natural gas (G2). This arrangement would certainly offer an optimal solution for the present waste management needs, fulfilling the European standards regarding recycling, valorization, and elimination of this waste. It could also lower the energy consumption of the archipelago, potentially lowering its electricity costs.

A model emerges that integrates solid waste management in the port environment with the production of exploitable energy from this waste. Thus, its recyclable components can be sorted and energy can be generated from otherwise valueless materials (cf. Table 2). In this way, an almost free electricity generation source appears that can supply the main port demand if backed up by liquefied natural gas transported via the virtual gas pipeline from the plant being installed at the new port in Granadilla (southern Tenerife).

Before continuing, it is important to explain Figure 4, since it shows the study procedure. Based on the data obtained from the Port Authority, the waste to be treated must be quantified and characterized. The quantities of waste classified under the Fifth MARPOL Convention annex and other associated types collected from ships using the port, are clearly insufficient for electricity generation once valorized as energy. For this reason, waste flows from companies operating in the port of Santa Cruz are also included and studied here. 


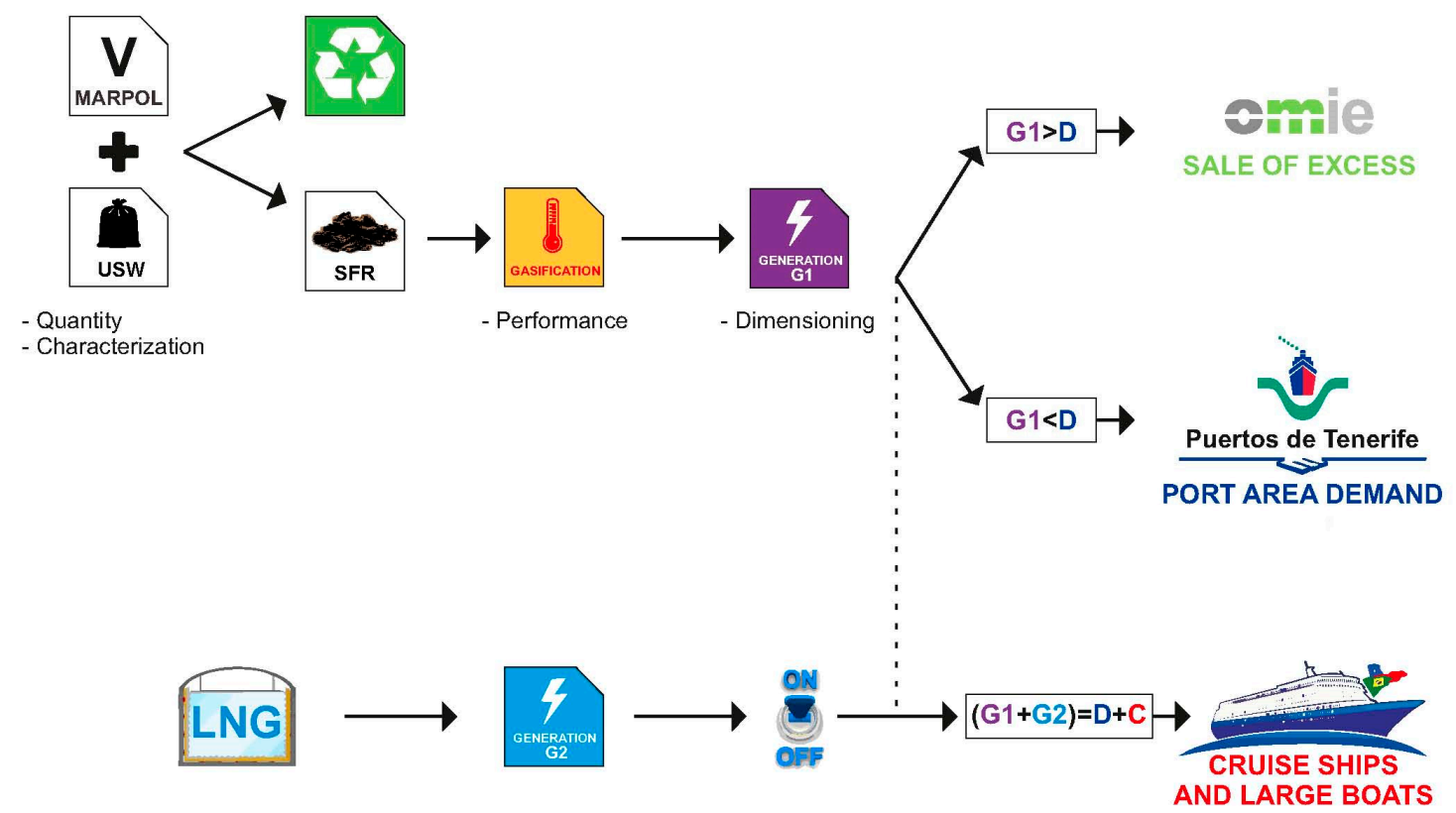

Figure 4. Proposed model of energy generation from port waste.

Table 2. Annual estimate of Santa Cruz dock waste not included in the MARPOL Convention annexes (Data provided by Canary Bionergy S.L.).

\begin{tabular}{cccccc}
\hline \multicolumn{7}{c}{ Port of Santa Cruz de Tenerife 2015 (kg) } & & \\
\hline Designation of Waste & Destination & $\begin{array}{c}\text { Annual } \\
\text { Estimate }\end{array}$ & $\begin{array}{c}\text { Total } \\
\text { Recoverable }\end{array}$ & $\begin{array}{c}\text { Total } \\
\text { Recyclable }\end{array}$ & $\begin{array}{c}\text { Total Not } \\
\text { Useful }\end{array}$ \\
\hline URBAN SOLID WASTE & Valorization & $254,830.00$ & $254,830.00$ & - & - \\
PAPERBOARD & Valorization & 7858.00 & 7858.00 & - & - \\
PAPERBOARD & Recycling & 2040.00 & - & 2040.00 & - \\
PACKAGING-PLASTIC & Recycling & 1144.00 & - & 1144.00 & - \\
WOOD & Valorization & $12,610.00$ & $12,610.00$ & - & - \\
DEBRIS-LAND & Environmental complex & $67,238.00$ & - & - & $67,238.00$ \\
ROAD CLEANING & Environmental complex & $64,700.00$ & - & - & $64,700.00$ \\
VEGETABLE PRUNING & Valorization & $10,500.00$ & $10,500.00$ & - & - \\
CABLES & Valorization & $11,220.00$ & $11,220.00$ & - & - \\
\hline TOTAL & & & $\mathbf{2 9 7 , 0 1 8 . 0 0}$ & $\mathbf{3 1 8 4 . 0 0}$ & $\mathbf{1 3 2 , 1 1 9 . 0 0}$ \\
\hline
\end{tabular}

The refuse processing plant's input would consist of the following fractions: glass, rubber, rubble, disposable nappies and other cellulose, organic matter, paper and cardboard, plastic film, ferric and non-ferric materials, textiles, wood, other plastics, batteries, and others. These fractions can be found in proportions established after characterizing samples collected over the recent study period. These data aid in deciding the potential of separating each fraction, as well as the size of the plant needed.

To estimate the seasonal nature of waste streams, data from the Port Authority help to see the months in which there is more port traffic, that is, more waste reception and more electricity consumption. Unlike the Mediterranean coast, in the Canary Islands the low season coincides with the months of May, June and August. In the other months, the island receives a large number of tourists, who temporarily escape from the colder countries.

In the case of the two main ports of the Canary Islands, MARPOL V data collected per year estimate an amount of $16,450.47 \mathrm{~m}^{3}$ for the province of Santa Cruz and $39,481.13 \mathrm{~m}^{3}$ for the port of Las Palmas. In Section 3 the diagram of the proposed process is described. 


\subsection{Waste Management Data}

Currently, Santa Cruz docks receive MARPOL V waste from ships using their services. Owing to some industrial, business and service facilities also being located there, there is a solid refuse collection network consisting of a selective pick-up of recyclables and the bulk collection of the remaining fraction. Thus, the total flow from both currents is sent to the corresponding processing and land-fill sites. According to the last data series from the Port of Santa Cruz Authority, the average flow is $21,020 \mathrm{~m}^{3}$ of MARPOL V and $65,709 \mathrm{~m}^{3}$ of solid waste, generated by licensed companies within the docks. Based on this volume, the port zone itself could be treated as an isolated waste treatment center.

Marine and dockside ship-waste pick-up and reception services in Santa Cruz operate continuously 365 days a year. There are no treatment plants in the docks for this kind of waste, which directly incurs disposal costs for the port authorities. According to the data compiled, there were 2927 waste receiving services rendered in 2015 in Santa Cruz docks (without considering other associated ports in the same province, like La Palma, El Hierro, La Gomera or Los Cristianos), with a total solid waste volume of 15,715 $\mathrm{m}^{3}$ (MARPOL V). Likewise, for the years 2013 and 2015, there is an increasing evolution of MARPOL $\mathrm{V}$ generated in the western ports of the archipelago. The average of MARPOL $\mathrm{V}$ generated in the four western islands (La Gomera, La Palma, Tenerife, and El Hierro) reaches the value of 21,019.00 $\mathrm{m}^{3}$. In this study, waste not counted within Annex $\mathrm{V}$ but still to be managed has been included. Table 2 shows the average annual collection in Santa Cruz docks and the exploitable fraction to be evaluated (except glass and septic tank sludge, which are handled differently).

Table 3 shows a summary of data referring to 2013-2016, categorizing waste into paper, plastic and urban solid waste (USW) and similar. Importantly, the volume of waste generated by such companies rose yearly, a clear sign of the trend toward growth in tourism and services on the island.

Table 3. Wastes generated by licensed companies operating in Santa Cruz docks in the 2013-2016 period (Data provided by Canary Bioenergy S.L.).

\begin{tabular}{ccccc}
\hline Waste $\left(\mathbf{m}^{\mathbf{3}}\right)$ & $\mathbf{2 0 1 3}$ & $\mathbf{2 0 1 4}$ & $\mathbf{2 0 1 5}$ & $\mathbf{2 0 1 6}$ \\
\hline Paper & 4080.00 & 5120.00 & 6160.00 & 7558.20 \\
Plastic & 4264.00 & 4896.00 & 5528.00 & 6136.08 \\
USW & $52,854.40$ & $58,281.60$ & $65,708.80$ & $73,593.86$ \\
\hline
\end{tabular}

\subsection{Data on Energy Consumption in the Port of Santa Cruz de Tenerife}

It is necessary to make a rough forecast of demand for one year. From this, we can compile some interesting data, for instance regarding the need for a generation source capable of meeting the peaks of demand caused by ship dockings coinciding on the same or very close dates.

According to data gathered by the Port Authority of Santa Cruz de Tenerife, the average estimate of consumption per cruise-ship is 3.9 MW, which corresponds to an average berth of $11.4 \mathrm{~h}$ and 1.6 cruises per day. As seen in Figure 5, depending only on the demand from the docked ships, energy consumption varies greatly from $5.8 \mathrm{MW} /$ day minimum to a $33.3 \mathrm{MW} /$ day maximum when the cruise-ships coincide in the port, stimulating more activity. Taking this into account, a base load of $4 \mathrm{MW}$ is needed to keep the facilities running. 


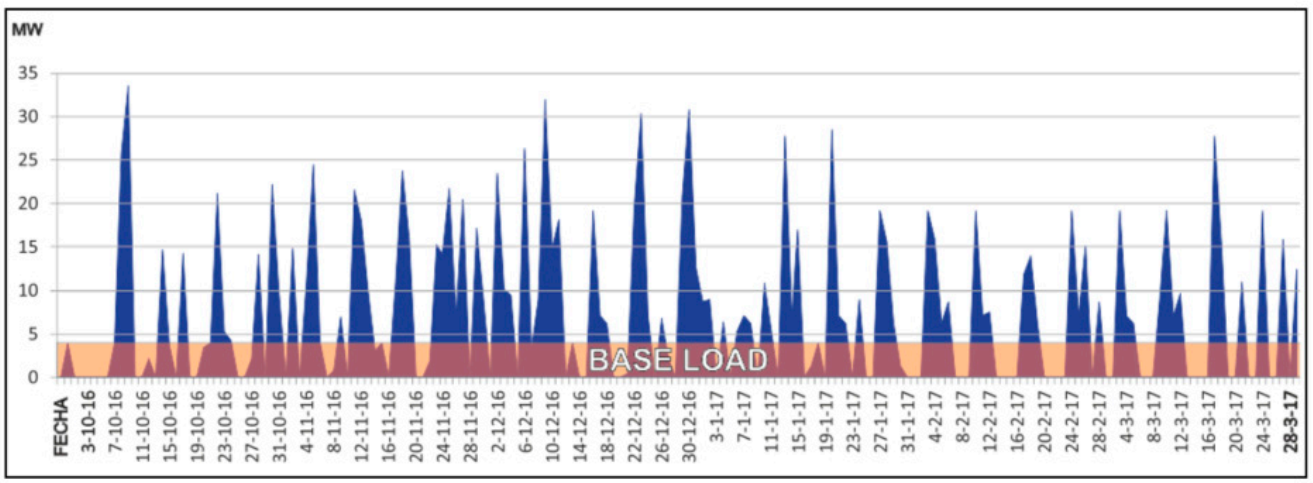

Figure 5. Estimated base load and energy peaks for a one-year period in the port of Santa Cruz de Tenerife.

\section{Results}

Figure 6 shows a comparison between the current waste management in the port and this proposal based on the concept of the circular economy, as put forward by other authors like Pauli [35] and Cubiña [36]. The model is based on not sending all the waste out to a general processing center, so as to create a micro-circular economy based on it. After processing, around 56\% would be used to produce electrical energy for the port's own consumption and when needed, for the ships (Figure 6). The expression that guides the model according to the hours of operation, the density of the waste and the fraction destined for recovery, is the following:

$$
\mathrm{E}=\mathrm{M}_{\mathrm{WtE}} \times \mathrm{PCI} / \mathrm{H}_{\mathrm{f}}
$$

where: $\mathrm{E}$ is the energy from the recovery of MARPOL waste (MW); $\mathrm{M}_{\mathrm{WtE}}$ is the fraction of waste that is converted annually (tons); PCI is the lower calorific value of the waste stream (Kcal/kg), and $\mathrm{H}_{\mathrm{f}}$ is the equivalent hours of operation of the plant.

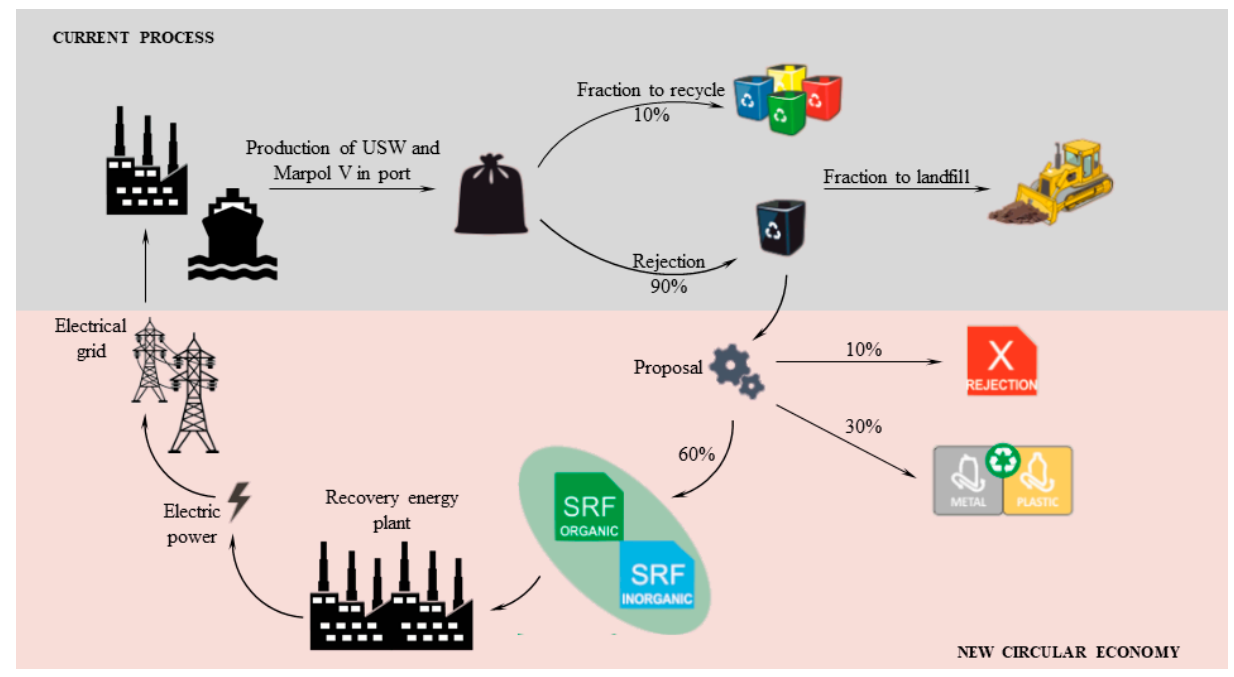

Figure 6. Suggested model, based on the 'circular economy' concept.

The following results have taken into account the methodology described in Section 2. For the prediction of the generation of energy and, therefore, the generation of waste in the port area, two premises have been considered: the first one is the evolution of the arrival of cruises to the island over the last five years and, the second one is the existing forecast of cruises for the coming years in the islands (these are facts that the ports have well in advance in order to foresee the demand for services). Table 4 shows a summary of the statistics and parameters considered in the study. Certain premises 
are necessary for replicating this study and applying it to other comparable isolated environments, which contribute positively to enriching it.

Table 4. Estimated results of waste treatment according to the flow processed.

\begin{tabular}{ccccc}
\hline \multicolumn{5}{c}{ Estimation of Results According to the Data and Characterizations Carried Out } \\
\hline Waste stream & Density $\left(\mathrm{kg} / \mathrm{m}^{3}\right)$ & Calorific value $(\mathrm{Kcal} / \mathrm{kg})$ & Moisture $(\%)$ & Quantity (Tn) \\
\hline MARPOL V & 300 & 741.19 & $45 \%$ & 4935.14 \\
Other solid waste from ships & 300 & 741.19 & $45 \%$ & 297.02 \\
Urban Solid Waste (USW) & 335 & 1258.81 & $40 \%$ & $22,012.49$ \\
\hline TOTAL & & & $\mathbf{2 7 , 2 4 4 . 6 5}$ \\
\hline Processed flow & Percentage (\%) & Energy capacity (MW) & Quantity (Tn) \\
\hline Fraction to recycle & 30 & - & 8173.40 \\
Fraction to rejection & 10 & - & 2669.98 \\
Energy fuel & 60 & 2.30 & $16,401.27$ \\
\hline TOTAL & $\mathbf{1 0 0}$ & $\mathbf{2 . 3 0}$ & $\mathbf{2 7 , 2 4 4 . 6 5}$ \\
\hline
\end{tabular}

Average waste density values have been taken from the characterizations performed, and match the interval corresponding to non-compact waste, as described in the CRC Handbook of Environmental Control [37]. For the study, a round figure for the average refuse density of $1000 \mathrm{~kg} / \mathrm{m}^{3}$ has been used, corresponding to waste compacted during the collection process, since factors such as water content affecting such refuse are highly variable. The reason lies in their dependence on organic content, the local weather conditions, on the way they are contained or presented and on their origin. Characterization of the non-compact wastes indicates a humidity content varying from $40 \%$ to $60 \%$ by weight.

The data point to a capability of extracting 2.3 MW of electricity for the port's own consumption, generated only from waste not currently recycled, which moreover currently incurs financial losses through disposal costs.

However, these results need an extrapolation in two directions. First, and following the marked evolution of previous years, it is useful to quantify energy savings in a five-year perspective. Second, it is useful to extend the study to at least the other provincial capital, Las Palmas de Gran Canaria. It is necessary to clarify some previous premises. There is not much data available from the port authority of the province of Las Palmas. Nevertheless, it is accepted, according to data from the published archives of State Ports of the Ministry of Public Works of Spain [38], that the activity of garbage collection in the docks of the port of the Gran Canaria capital is about three times as much as that of the port of Santa Cruz de Tenerife. Hence, with the same calculation assumptions as before, the quantities of garbage estimated by the provincial capital are shown in the range of years between 2015 and 2020 (see Table 5).

Table 5. Estimated waste generated between 2015-2020 for Santa Cruz de Tenerife and Las Palmas de Gran Canaria (Tn).

\begin{tabular}{ccccccccc}
\hline \multicolumn{4}{c}{ Santa Cruz de Tenerife } & \multicolumn{3}{c}{ Las Palmas de Gran Canaria } \\
\hline Year & $\begin{array}{c}\text { MARPOL } \\
\text { V }\end{array}$ & $\begin{array}{l}\text { Other solid } \\
\text { waste from } \\
\text { ships }\end{array}$ & USW & $\begin{array}{c}\text { Total } \\
\text { quantity } \\
\text { per year }\end{array}$ & $\begin{array}{c}\text { MARPOL } \\
\text { V }\end{array}$ & $\begin{array}{c}\text { Other solid } \\
\text { waste from } \\
\text { ships }\end{array}$ & USW & $\begin{array}{c}\text { Total } \\
\text { quantity } \\
\text { per year }\end{array}$ \\
\hline $\mathbf{2 0 1 5}$ & 4935.14 & 297.20 & $19,712.64$ & $24,944.98$ & $14,805.42$ & 891.60 & $59,137.92$ & $74,834.94$ \\
$\mathbf{2 0 1 6}$ & 5231.25 & 326.92 & $22,078.16$ & $27,636.33$ & $15,693.75$ & 980.76 & $66,234.48$ & $82,908.99$ \\
$\mathbf{2 0 1 7}$ & 5545.12 & 362.88 & $24,727.53$ & $30,635.53$ & $16,635.36$ & 1088.64 & $74,182.59$ & $91,906.59$ \\
$\mathbf{2 0 1 8}$ & 5933.30 & 395.54 & $27,694.84$ & $34,023.68$ & $17,799.90$ & 1186.62 & $83,084.52$ & $102,071.04$ \\
$\mathbf{2 0 1 9}$ & 6467.28 & 431.14 & $31,018.22$ & $37,916.64$ & $19,401.84$ & 1293.42 & $93,054.66$ & $113,749.92$ \\
$\mathbf{2 0 2 0}$ & 7114.00 & 465.63 & $34,740.40$ & $42,320.03$ & $21,342.00$ & 1396.89 & $104,221.20$ & $126,960.09$ \\
\hline Total & \multicolumn{3}{c}{$\mathbf{1 9 7 , 4 7 7 . 1 9}$} \\
\hline
\end{tabular}


In a more compact way, and with the same previous characterization assumptions, Table 6 shows the estimate for both provinces once the model for the period 2015-2020 has been applied.

Table 6. Estimated results of waste treatment for both islands.

\begin{tabular}{cccccccc}
\hline Santa Cruz de Tenerife & $\mathbf{2 0 1 5}$ & $\mathbf{2 0 1 6}$ & $\mathbf{2 0 1 7}$ & $\mathbf{2 0 1 8}$ & $\mathbf{2 0 1 9}$ & $\mathbf{2 0 2 0}$ & TOTAL \\
\hline Fraction to recycle (Tn) (30\%) & 8173.45 & 8290.90 & 9190.66 & $10,207.10$ & $11,374.99$ & $12,696.01$ & $59,243.16$ \\
Fraction to rejection (Tn) (10\%) & 2724.47 & 2763.63 & 3063.55 & 3402.37 & 3791.66 & 4232.00 & $19,977.69$ \\
Energy fuel (Tn) (60\%) & $16,364.79$ & $16,581.80$ & $18,381.32$ & $20,414.21$ & $22,749.98$ & $25,392.02$ & $119,392.02$ \\
\hline Total Energy (MW) & $\mathbf{2 . 1 7}$ & $\mathbf{2 . 2 0}$ & $\mathbf{2 . 4 4}$ & $\mathbf{2 . 7 1}$ & $\mathbf{3 . 0 2}$ & $\mathbf{3 . 3 7}$ & $\mathbf{1 5 . 9 1}$ \\
\hline Las Palmas de Gran Canaria & $\mathbf{2 0 1 5}$ & $\mathbf{2 0 1 6}$ & $\mathbf{2 0 1 7}$ & $\mathbf{2 0 1 8}$ & $\mathbf{2 0 1 9}$ & $\mathbf{2 0 2 0}$ & TOTAL \\
\hline Fraction to recycle (Tn) (30\%) & $24,520.19$ & $24,872.70$ & $27,571.98$ & $30,621,31$ & $34,124.98$ & $38,088.03$ & $179,799.17$ \\
Fraction to rejection (Tn) (10\%) & 8173.40 & 8290.90 & 9190.66 & $10,207.10$ & $11,374.99$ & $12,696.01$ & $59,933.06$ \\
Energy fuel (Tn) (60\%) & $49,040.37$ & $49,745.39$ & $55,143.95$ & $61,242.62$ & $68,249.95$ & $76,176.05$ & $359,598.35$ \\
\hline Total Energy (MW) & $\mathbf{6 . 5 1}$ & $\mathbf{6 . 6 0}$ & $\mathbf{7 . 3 2}$ & $\mathbf{8 . 1 3}$ & $\mathbf{9 . 0 6}$ & $\mathbf{1 0 . 1 1}$ & $\mathbf{4 7 . 7 4}$ \\
\hline
\end{tabular}

Similarly, in Figures 7 and 8, it is possible to compare the evolution of the energy contribution for self-consumption in a five-year interval, the waste that is destined for the recovery and the fraction that is recycled in each of the provinces.

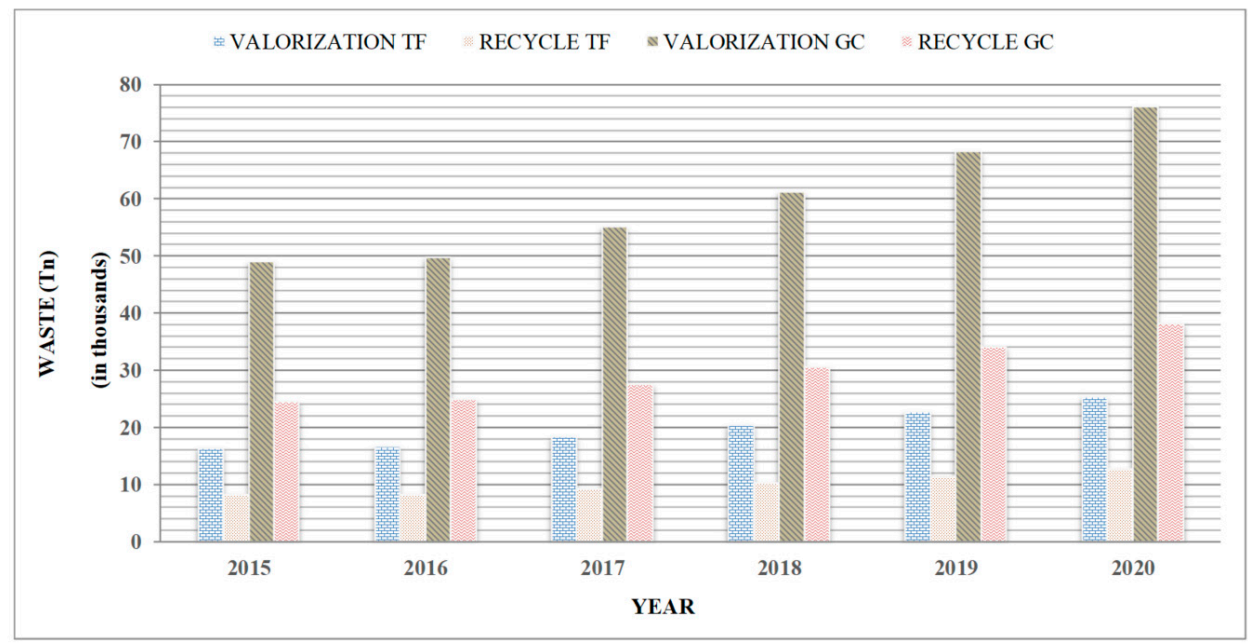

Figure 7. Estimated results of waste treatment in both islands about valorization.

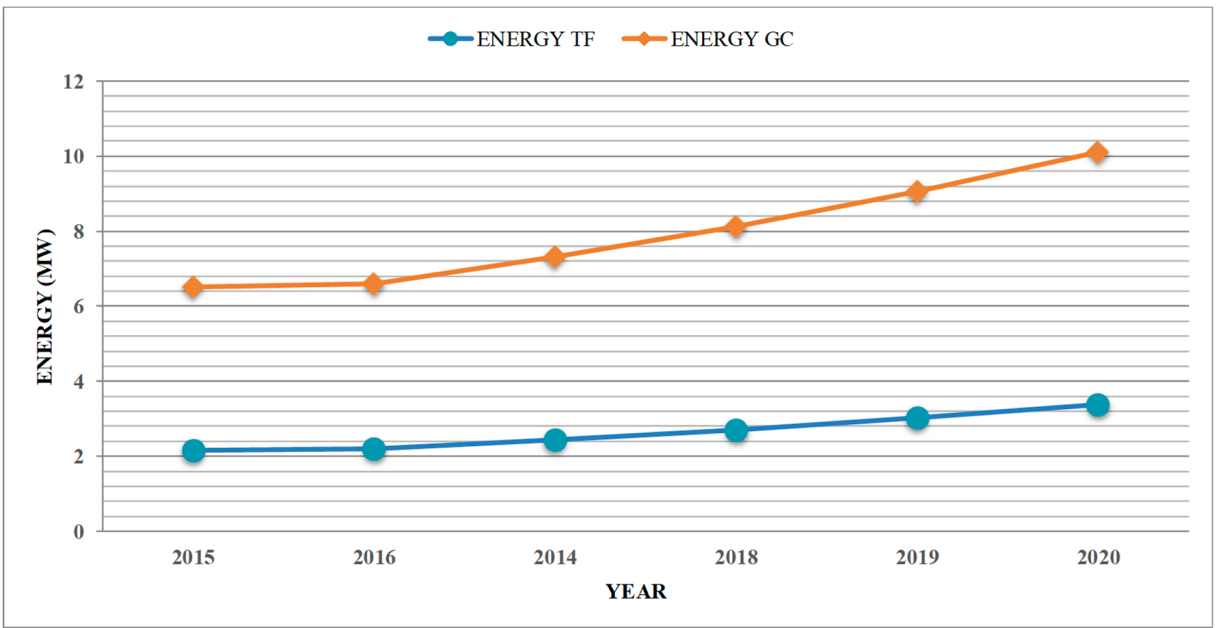

Figure 8. Estimated results of waste treatment in both islands about recycling. 


\section{Discussion}

The data coming from these islands, where transport and recycling are a serious problem in the management of waste, are very encouraging. As explained by Rodríguez [39] and Uche-Soria and Rodríguez-Monroy [40], their isolated condition and the few infrastructures of these subsystems require a constant study of alternatives for improvement. According to this model, the capital port of Las Palmas can get up to 47.74 MW of waste energy per year from Marpol V. In the province of Santa Cruz de Tenerife the results are more modest (15.91 MW per year). However, it is important to note that this energy comes from an improvement in current waste management and provides many advantages: reduction of waste transport to the landfill, lower emission of greenhouse gases, reduction of $\mathrm{CO}_{2}$ generated by transport and an increase in the recycling fraction.

It is interesting to compare the proposed solution to others that could be applied in this isolated environment. The first alternative consists of leaving things as they are, implementing no improvements. The second is to apply in practice the model deriving from the present study, and finally, a third intermediate situation where only waste management is improved (investment in recycling) but waste is not valorized as energy. Based on the current legislation, economic, functional, environmental and social indicators have been used in this analysis.

This multicriteria analysis (Table 7) is inclined favorably towards the proposed model, bearing in mind the limitations to precision derived from this being a modest study in scale and means, and from the selected methodology. With the exception of the functional point of view within which the three options are found in the same legal and administrative framework, from the rest it seems that the second model shows the best approach. From the economic point of view, our proposal is the least arduous alternative for the port of Santa Cruz and would mean a substantial reduction in its current waste management costs. With this alternative, most of the waste produced can be valorized, considering that on one hand, recyclable materials are recovered, and on the other, electricity is produced for self-consumption. Additionally, more jobs would be created.

From an environmental point of view, the impact caused during the construction phase is minor. In the working phase, it could be minimized by applying the appropriate preventive and remedial measures. The current $\mathrm{CO}_{2}$ emissions coming from transport by road to the refuse processing and land-fill site would be reduced. From the social point of view, unpleasant odors or other annoyances to the population are not likely.

Based on the simulated results, several policy recommendations for the Canary Islands' ports can be provided. First, in isolated environments such as the Canary archipelago, the optimization of waste management can have significant positive effects, not only on aspects related to environmental pollution, but also on energy policy, helping to implement new solutions that allow more sustainable models.

Second, especially in isolated systems such as the Canary Islands, it is necessary to align the strategic thinking of the archipelago in energy and environmental matters with the development of legislation so that, far from penalizing, it contributes to investments to implement these and other measures that help improve the complex energy scheme of isolated electricity systems [41,42]. A clear example is the investment in circular economy policies taking advantage of the singularities of each island.

Third, this energy management would be an obvious improvement in the waste management service of Tenerife, according to the revised text of the Special Territorial Plan for the Management of Waste in Tenerife [43]. This entails a lower financial cost for the Port Authority and a great reduction in waste transport volume to the processing center (with the social and environmental repercussions that this currently implies). 
Table 7. Multicriteria analysis of waste-disposal alternatives for Tenerife's main port, Santa Cruz.

\begin{tabular}{|c|c|c|c|c|}
\hline \multicolumn{5}{|c|}{ Study Criteria } \\
\hline Alternatives & Economic & Environmental & Functional & Social \\
\hline $\begin{array}{c}\text { 1/Current situation: } \\
\text { without } \\
\text { intervention }\end{array}$ & $\begin{array}{l}\text { With the current management system, } \\
25,000 \text { tons of waste coming from the port, are } \\
\text { being taken to the environmental complex. } \\
\text { Its cost is around } 1,500,000 € \text { per year. } \\
\text { New employment opportunities would not } \\
\text { be created. }\end{array}$ & $\begin{array}{l}\text { Overloading of the landfill. } \\
\text { It is estimated that, given the number of } \\
\text { waste, a total number of } 2500 \text { journeys of } \\
\text { the garage trucks per year would be } \\
\text { necessary, which implies } 250 \text { tons of } \mathrm{CO}_{2} \\
\text { emissions per year. } \\
\text { There is no visual environmental impact. }\end{array}$ & $\begin{array}{l}\text { The current management } \\
\text { system of Santa Cruz's port } \\
\text { is viable from the technical } \\
\text { and legal/administrative } \\
\text { point of view. }\end{array}$ & $\begin{array}{l}\text { Risks of accidents and withholdings } \\
\text { due to the journeys to the landfill. } \\
\text { Increase of municipal taxes of the } \\
\text { landfill due to clogging. }\end{array}$ \\
\hline 2/Recovery of waste & $\begin{array}{c}\text { Only } 2500 \text { tons of waste (reduction of the } 90 \% \text { ), } \\
\text { are moved to the environmental complex, } \\
\text { which causes a decrease in the cost associated } \\
\text { to the charges of entry of the landfill. } \\
\text { New employment opportunities would } \\
\text { be created. }\end{array}$ & $\begin{array}{l}\text { There is not landfill overloading. } \\
\text { Reduction of truck journeys down to } 150, \\
\text { with } 15.36 \text { tons of } \mathrm{CO}_{2} \text { emissions per year. } \\
\text { Recycling of } 30 \% \text { of the products. } \\
\text { There is visual environmental impact. }\end{array}$ & $\begin{array}{l}\text { The management system of } \\
\text { waste of recovery proposed } \\
\text { is viable from the technical } \\
\text { and legal/administrative } \\
\text { point of view. }\end{array}$ & $\begin{array}{l}\text { Less accident risks and retentions } \\
\text { due to the journeys to the landfill. } \\
\text { Improvement of the management } \\
\text { system of waste in line with the } \\
\text { Tenerife's Special Territorial Waste } \\
\text { Management Plan (PTEOR). }\end{array}$ \\
\hline $\begin{array}{c}\text { 3/Separation in } \\
\text { origin of recyclable } \\
\text { materials }\end{array}$ & $\begin{array}{c}19,071.25 \text { tons of rejections of end of line per } \\
\text { year are moved to the environment complex } \\
\text { after the separation for recycling (reduction of } \\
\text { the } 30 \% \text { ). } \\
\text { Its cost would be about } 2,000,000 € \text { per year. } \\
\text { New employment opportunities would be } \\
\text { created (although they would be less than in } \\
\text { option 2). }\end{array}$ & $\begin{array}{l}\text { The junkyard elimination gets reduced } \\
\text { when compared to the current situation. } \\
\text { Reduction of the trucks to } 1076 \text { journeys, } \\
\text { with } 110.3 \text { tons of } \mathrm{CO}_{2} \text { emissions per year. } \\
\text { Recycling of } 30 \% \text { of the waste. } \\
\text { There is visual environmental impact. }\end{array}$ & $\begin{array}{l}\text { The management system of } \\
\text { waste of separation } \\
\text { proposed is viable from the } \\
\text { technical and } \\
\text { legal/administrative point } \\
\text { of view. }\end{array}$ & $\begin{array}{l}\text { Traffic caused by the waste } \\
\text { transport is reduced by } 43 \% \text {. }\end{array}$ \\
\hline
\end{tabular}


Fourth, applying the proposed model the island's general waste management system is largely liberated of responsibility, overcoming difficulties such as coordination with its management network. This involves considerable daily transport costs to the Port Authority (nearly $60 \mathrm{~km}$ daily for each journey).

Fifth, considering that the annual amount of waste produced is nearly 30,000 tons, it is of vital importance to have a total control over the management of that flow. This opens the door to reaching higher levels of efficiency in terms of recycling the waste materials produced that would considerably benefit the main port of Tenerife and its activity. This proposal implies that the port recovers nearly 30\% of the reusable materials from the total waste accumulated, as well as providing better management of MARPOL V waste from the ships using its facilities. Additionally, the proportion of journeys carried out for transporting waste to the landfill is greatly reduced (by nearly $90 \%$ ).

Sixth, it is a good opportunity to study the peculiarities of the isolated systems in more detail, regarding technologies, plans for development in small systems and the legislative framework in force. The regulations, technology, and investment levels are lacking appropriate adaptation to these isolated environments. As an example, although in this article the isolated system of the port of Santa Cruz was analyzed, the authors consider that replicating this study and others related to the energy planning of each subsystem in the Canary Islands' IES would also be of great value. Smaller islands in the archipelago like La Gomera, El Hierro or La Palma would be of special interest since the cost of electricity generation there is even higher and there are as yet no optimized solutions in the field of waste processing and disposal providing guidelines in pursuing a circular economy.

Beyond the technology or the money available to invest in infrastructure, the main limitation that authors find to carry out this model of energy management is the short-term vision of the actors involved in the energy planning of countries, cities, ports and small subsystems. The development of energy policies in these environments consists of short-term measures that, while solving a current need, at the same time create a problem in the medium term through policies that negatively influence an energy transition. As Fusco [44] points out in his study on smart sustainable development in cities and port areas, information and communication technology (ICT), innovative technologies and approaches such as the circular economy to implement new policies cannot be missed. However, it must be admitted that this new approach requires a considerable cultural change on the side of society and of the companies and authorities that intervene in the transition.

\section{Conclusions}

This study shows the authors' interest in searching for alternatives to improve the current issue of waste management and energy sustainability in isolated systems, with a special emphasis on the Canary Islands and other non-mainland locations.

Furthermore, this study is focused on the need to improve Tenerife's energy planning, in order to arrive at a model that can be replicated in other similar isolated systems like the Cape Verde Islands or the Azores Islands, which, like the Canary Islands, have similar problems related to the security of supply, the price of energy and waste management. For this reason, the possibility of the port of Santa Cruz being an autonomous system regarding its own waste management and energy supplies, for both dockside facilities and cargo ships, ferries and cruise liners stopping over the island, is a relevant study. A key advance would be a preliminary study to clarify the current energy situation, quantifying and characterizing the existing waste flows, and to design a configuration integrating the different solutions available for each aspect.

Author Contributions: Both authors have participated directly in performing this research. M.U.-S. has been responsible for gathering the relevant data, processing these data, and writing the original draft. C.R.-M. has been responsible for the design of the research project and the supervision of its development.

Funding: There was no financial founding to support this research.

Acknowledgments: This study is partly supported by Canary Bioenergy, S.L. (CANBE) that works on projects of energy solutions for the islands, especially focused on the Canary Islands' needs. 
Conflicts of Interest: The authors declare no conflict of interest.

\section{References}

1. Gobierno de Canarias. Canary Islands Energy Yearbook 2017. Available online: http://www. gobiernodecanarias.org/ceic/energia/doc/Publicaciones (accessed on 26 February 2019).

2. Guerrero-Lemus, R.; González-Díaz, B.; Ríos, G.; Dib, R.N. Study of the new Spanish legislation applied to an insular system that has achieved grid parity on PV and wind energy. Renew. Sustain. Energy Rev. 2015, 49, 426-436. [CrossRef]

3. Marrero, G.A.; Ramos-Real, F.J. Electricity generation cost in isolated systems: The complementarities of natural gas and renewables in the Canary Islands. Renew. Sustain. Energy Rev. 2010, 14, 2808-2818. [CrossRef]

4. Mendoza-Vizcaino, J.; Sumper, A.; Sudria-Andreu, A.; Ramirez, J.M. Renewable technologies for generation systems in islands and their application to Cozumel Island, Mexico. Renew. Sustain. Energy Rev. 2016, 64, 348-361. [CrossRef]

5. Fokaides, P.A.; Kulili, A. Toward grid parity in insular energy systems: The case of photovoltaics (PV) in Cyprus. Energy Policy 2013, 65, 223-228. [CrossRef]

6. Kuang, Y.; Zhang, Y.; Zhou, B.; Li, C.; Cao, Y.; Li, L.; Zeng, L. A review of renewable energy utilization in islands. Renew. Sustain. Energy Rev. 2016, 59, 504-513. [CrossRef]

7. Royal Decree 738/2015, of July 31, Which Regulates the Activity of Electric Power Production and the Dispatch Procedure in the Electrical Systems of the Non-Peninsular Territories. Official State Bulletin, N. 183 of 1 August 2015. BOE-A-2015-8646. Available online: https://www.boe.es/eli/es/rd/2015/07/31/738 (accessed on 25 June 2018).

8. Royal Decree 413/2014, of June 6, Which Regulates the Activity of Production of Electric Power from Renewable Sources of Energy, Cogeneration and Residues. Official State Bulletin, N. 140 of 10 June 2014. BOE-A-2014-6123. Available online: https://www.boe.es/eli/es/rd/2014/06/06/413/con (accessed on 30 June 2018).

9. Royal Decree 900/2015, of October 9, Which Regulates the Administrative, Technical and Economic Conditions of the Modalities of Electric Power Supply with Self-consumption and Production with Self-consumption. Official State Bulletin, N. 243 of 10 October 2014. BOE-A-2015-10927. Available online: https://www.boe.es/ eli/es/rd/2015/10/09/900 (accessed on 26 June 2018).

10. Iñiguez, M.E.; Conesa, J.A.; Fullana, A. Marine debris occurrence and treatment: A review. Renew. Sustain. Energy Rev. 2016, 64, 392-402. [CrossRef]

11. Adolf, K.Y.; Song, S. The environmental impacts of pollutants generated by routine shipping operations on ports. Ocean Coast. Manag. 2010, 53, 301-311.

12. Di Vaio, A.; Varriale, L.; Trujillo, L. Management Control Systems in port waste management: Evidence from Italy. Util. Policy 2019, 56, 127-135. [CrossRef]

13. Di Vaio, A.; Varriale, L. Management Innovation for Environmental Sustainability in Seaports: Managerial Accounting Instruments and Training for Competitive Green Ports beyond the Regulations. Sustainability 2018, 10, 783. [CrossRef]

14. Onwuegbuchunam, D.E.; Ebe, T.E.; Okoroji, L.I.; Essien, A.E. An Analysis of Ship-Source Marine Pollution in Nigeria Seaports. J. Mar. Sci. Eng. 2017, 5, 39. [CrossRef]

15. External Costs of Transport: Accidents, Environmental and Congestion Costs of Transport in Western Europe; INFRAS/IWW; International Union of Railways: Paris, France, 2000.

16. Etkin, D.S. Modeling oil spill response and damage costs. In Proceedings of the 2003 International Oil Spill Conference; American Petroleum Institute: Washington, DC, USA, 2003.

17. Camphuysen, C.J. Chronic Oil Pollution in Europe; A Status Report; IFAW: Brussels, Belgium, 2007.

18. Adler, E.; Inbar, M. Shoreline sensitivity to oil spills, the Mediterranean coast of Israel: Assessment and analysis. Ocean Coast. Manag. 2007, 50, 24-34. [CrossRef]

19. Gómez, A.G.; Ondiviela, B.; Puente, A.; Juanes, J.A. Environmental risk assessment of water quality in harbour areas: A new methodology applied to European ports. J. Environ. Manag. 2015, 155, 77-88. [CrossRef] [PubMed]

20. Liu, X.; Wirtz, K.W. Total oil spill costs and compensations. Marit. Policy Manag. 2006, 33, 49-60. [CrossRef] 
21. Etkin, D.S. Estimating cleanup costs for oil spills. In Proceedings of the 1999 International Oil Spill Conference; American Petroleum Institute: Washington, DC, USA, 1999.

22. Moreno-Gutiérrez, J.; Pájaro-Velázquez, E.; Amado-Sánchez, Y.; Rodríguez-Moreno, R.; Calderay-Cayetano, F.; Durán-Grados, V. Comparative analysis between different methods for calculation on-board ship's emissions and energy consumption based on operational data. Sci. Total Environ. 2019, 650, 575-584. [CrossRef] [PubMed]

23. Kumar, J.; Kumpulainen, L.; Kauhaniemi, K. Technical design aspects of harbour area grid for shore to ship power: State of the art and future solutions. Electr. Power Energy Syst. 2019, 104, 840-852. [CrossRef]

24. Yigit, K.; Acarkan, B.; Yigit, K. A new electrical energy management approach for ships using mixed energy sources to ensure sustainable port cities. Sustain. Cities Soc. 2018, 40, 126-135. [CrossRef]

25. Kirchherr, J.; Reike, D.; Hekkert, M. Conceptualizing the circular economy: An analysis of 114 definitions. Resour. Conserv. Recycl. 2017, 127, 221-232. [CrossRef]

26. Geissdoerfer, M.; Savaget, P.; Bocken, N.; Hultink, E.J. The Circular Economy-A new sustainability paradigm? J. Clean. Prod. 2017, 143, 757-768. [CrossRef]

27. Carpenter, A.; Lozano, R.; Sammalisto, K.; Astner, L. Securing a port's future through Circular Economy: Experiences from the Port of Gävle in contributing to sustainability. Mar. Pollut. Bull. 2018, 128, 539-547. [CrossRef]

28. Articles, Protocols, Annexes and Unified Interpretations of the International Convention for the Prevention of Pollution from Ships, 1973, as Modified by the Protocol of 1978, Consolidated Edition; MARPOL 73/78; OMI: London, UK, 2002.

29. Amendments to the Annex of the International Convention for the Prevention of Pollution from Ships, 1973, as Modified by the Protocol of 1978 Relating Thereto. Amendments to MARPOL Annex V, 2018. Available online: https://www.irclass.org/media/3243/mepc-277-70.pdf (accessed on 15 October 2018).

30. Directive 2000/59/EC of the European Parliament and of the Council of 27 November 2000 on Port Reception Facilities for Ship-Generated Waste and Cargo Residues-Commission Declaration. Official Journal of the European Union 28/12/2000; OJ L332:0081-0090. Available online: https:/eur-lex.europa.eu/eli/dir/2000/59/oj (accessed on 15 October 2018).

31. Royal Decree 1381/2002, of December 20, on Port Facilities for Waste Generated by Ships and Cargo Residues. Official State Bulletin, N. 305 of 21 December 2002. BOE-A-2002-24910. Available online: https://www.boe.es/eli/es/rd/2002/12/20/1381 (accessed on 20 July 2018).

32. Bellas, J. The implementation of the Marine Strategy Framework Directive: Shortcomings and limitations from the Spanish point of view. Mar. Policy 2014, 50, 10-17. [CrossRef]

33. Directive 2008/56/EC of the European Parliament and of the Council of 17 June 2008, Establishing a Framework for Communityaction in the Field of Marine Environmental Policy (Marine Strategy Framework Directive). Off. J. Eur. Union 2008, 164, 19-40.

34. Directive 2009/72/EC of the European Parliament and of the Council Concerning Common Rules for the Internal Market in Electricity and Repealing Directive 2003/54/EC. Official Journal of the European Union 14/08/2009. OJ L211:55-93. Available online: https://eur-lex.europa.eu/eli/dir/2009/72/oj (accessed on 25 October 2018).

35. Pauli, G. Technology Forecasting and Assessment: The Case of Zero Emissions. Technol. Forecast. Soc. Chang. 1998, 58, 53-62. [CrossRef]

36. Cubiñá, I. Cradle to cradle: Diseñando en abundancia. Investig. Mark. 2010, 109, 64-68.

37. Bond, R.G.; Straub, C.P.; Prober, R. Handbook of Environmental Control; CRC Press: Boca Raton, FL, USA, 1972.

38. Ports of the State of the Ministry of Public Works of Spain Website. Available online: http://www.puertos.es/ es-es/estadisticas (accessed on 10 January 2018).

39. Rodríguez, M. The Non-Peninsular Electrical Systems. Power Noteb. 2014, 42, 5-12. Available online: https://dialnet.unirioja.es/servlet/articulo?codigo=4790044 (accessed on 29 October 2018).

40. Uche-Soria, M.; Rodríguez-Monroy, C. Special Regulation of Isolated Power Systems: The Canary Islands, Spain. Sustainability 2018, 10, 2572. [CrossRef] 
41. Ministry of Industry, Energy and Tourism. Energy Planning. Development Plan of the Energy Transport Network 2015-2020 of the Government of Spain. 2015. Available online: http://www.mincotur.gob.es/energia/planificacion/Planificacionelectricidadygas/desarrollo20152020/ Documents/Planificaci\%C3\%\%B3n\%202015_2020\%20\%202016_11_28\%20VPublicaci\%C3\%B3n.pdf (accessed on 8 December 2017).

42. Law 17/2013, of October 30, 2013, for the Guarantee of the Supply and Increase of the Competition in the Insular and Extra-Peninsular Electrical Systems. Official State Bulletin, N. 260 of 30 October 2013. BOE-A-2013-11332. Available online: https://www.boe.es/eli/es/1/2013/10/29/17 (accessed on 22 May 2018).

43. Consolidated text of the Special Territorial Plan of Waste Management of Tenerife. Cabildo Insular de Tenerife. 2011. Available online: http://www.tenerife.es/planes/PTEOResiduos/PTEOResiduosindex.htm (accessed on 29 October 2018).

44. Fusco, L. Toward a Smart Sustainable Development of Port Cities/Areas: The Role of the "Historic Urban Landscape" Approach. Sustainability 2013, 5, 4329-4348. [CrossRef]

(C) 2019 by the authors. Licensee MDPI, Basel, Switzerland. This article is an open access article distributed under the terms and conditions of the Creative Commons Attribution (CC BY) license (http://creativecommons.org/licenses/by/4.0/). 